\title{
Levantamento etnobotânico de plantas inseticidas em comunidades rurais de Alta Floresta - MT
}

\author{
Simone de Bitencourt Oliveira ${ }^{1 \star(D)}$, Mariane Kaori Sasaya ${ }^{1}$ (D), Juliana Garlet ${ }^{2}$ (D) \\ ${ }^{1}$ Programa de pós-graduação em Biodiversidade em Agroecossistemas Amazônicos, Universidade do Estado de Mato \\ Grosso, Av. Tancredo Neves, 1095 - Cavalhada III, Cáceres, Mato Grosso, 78217-900. \\ ${ }^{2}$ Departamento de Engenharia Florestal, Universidade do Estado de Mato Grosso, Av. Perimetral Rogério Silva, s/n, \\ Jardim Flamboyant, Alta Floresta, MT, 78580000. \\ * Autor para correspondência: simonedebitencourt@gmail.com
}

Recebido em 21 de julho de 2020.

Aceito em 26 de setembro de 2020.

Publicado em 30 de setembro de 2020.

Resumo - Os povos primitivos já utilizavam as plantas para auxiliá-los em seus problemas cotidianos, e as relações que os seres humanos estabelecem com os recursos vegetais são estudadas pela etnobotânica. Assim, o objetivo deste trabalho foi averiguar o conhecimento e uso de plantas no controle de insetos-praga por produtores familiares de comunidades rurais em Alta Floresta, MT. A pesquisa foi desenvolvida nas comunidades Central, Vila rural e Guadalupe, onde foram selecionados 15 produtores em cada comunidade de forma aleatória. Mais de 70\% dos entrevistados já haviam usado ou conheciam plantas que apresentam ação inseticida, 22 espécies foram registradas, e as mais citadas foram: Nicotiana tabacum L. (33\%), Azadirachta indica A. Juss. (22\%), Capsicum frutescens L. (11\%) e Cymbopogon winterianus Jowit (8\%). Os insetos citados nas entrevistas que podem ser controlados pelas plantas bioinseticidas pertencem às ordens: Diptera, Hemiptera, Hymenoptera, Lepidoptera e Siphonoptera. O presente trabalho confirmou o conhecimento etnobotânico dos agricultores, no entanto observa-se a necessidade de mais estudos e divulgação para estimular o uso destes produtos naturais. Pode-se verificar a necessidade de investigação a respeito das plantas endêmicas da região, pois existe uma grande riqueza de espécies, no entanto as utilizadas pelos produtores não são nativas.

Palavras-chave: Agricultores familiares. Bioinseticida botânico. Conhecimento empírico.

\section{Ethnobotanical survey of insecticided plants in communities from Alta Floresta - MT}

\begin{abstract}
Primitive peoples already used plants to aid them in their daily problems, and the relationships established by human beings with plant resources are studied by ethnobotany. Thus, the objective of this work was to investigate the knowledge and use of plants in the control of insect pests by family farmers in rural communities in Alta Floresta, MT. The research was carried out in the Central, Vila rural and Guadalupe communities, where 15 producers were selected in each community at random. More than $70 \%$ of the interviewees had already used or knew plants that have an insecticidal action; 22 species were registered, and the most cited were: Nicotiana tabacum L. (33\%), Azadirachta indica A. Juss. (22\%), Capsicum frutescens L. (11\%) and Cymbopogon winterianus Jowit (8\%). The insects mentioned in the interviews that can be controlled by bio-insecticidal plants belong to the orders: Diptera, Hemiptera, Hymenoptera, Lepidoptera and Siphonoptera. The present
\end{abstract}


study confirmed the ethnobotanical knowledge of farmers, however there is need for further studies and dissemination to encourage the use of these natural products. It is possible to verify the need for research regarding endemic plants in the region, as there is a great wealth of species, however those used by producers are not native.

Keywords: Family farmers. Botanical bioinsecticide. Empirical knowledge.

\section{Encuesta etnobotánica de plantas insecticidas en comunidades rurales de Alta Floresta - MT}

Resumen - Los pueblos primitivos ya usaban plantas para ayudarlos en sus problemas diarios y a etnobotánica estudia las relaciones que los seres humanos establecen con los recursos vegetales. Por lo tanto, el objetivo de este trabajo fue investigar el conocimiento y el uso de plantas en el control de plagas de insectos por parte de los agricultores familiares en las comunidades rurales de Alta Floresta, MT. La investigación se llevó a cabo en las comunidades de Central, Vila rural y Guadalupe, donde se seleccionaron al azar 15 productores en cada comunidad. Más del 70\% de los entrevistados ya habían usado o conocían plantas que tienen una acción insecticida, se registraron 22 especies, y las más citadas fueron: Nicotiana tabacum L. (33\%), Azadirachta indica A. Juss. (22\%), Capsicum frutescens L. (11\%) y Cymbopogon winterianus Jowit (8\%). Los insectos mencionados en las entrevistas que pueden ser controlados por plantas bioinsecticidas pertenecen a las órdenes: Diptera, Hemiptera, Hymenoptera, Lepidoptera y Siphonoptera. El presente estudio confirmó el conocimiento etnobotánico de los agricultores, sin embargo, existe la necesidad de más estudios y difusión para alentar el uso de estos productos naturales. Es posible verificar la necesidad de investigación sobre plantas endémicas en la región, ya que existe una gran riqueza de especies, sin embargo, las utilizadas por los productores no son nativas.

Palabras clave: Agricultores familiares. Bioinsecticida botánico. Conocimiento empírico.

\section{Introdução}

O uso das plantas faz parte da evolução humana e foram os primeiros recursos utilizados pelos povos primitivos para solucionar questões relacionadas à saúde e eventuais pragas ocorrentes em suas plantações (Takeara et al. 2017; Batista et al. 2019). O hábito de recorrer às propriedades químicas de certos vegetais se trata de uma das primeiras manifestações do homem para compreender e utilizar a natureza em seu próprio benefício (Brandelli 2017).

As relações que os seres humanos estabelecem com os recursos vegetais são estudadas pela etnobotânica, ciência que objetiva registrar os saberes botânico tradicionais, o qual se dá pela experiência empírica acumulada ao longo do tempo pelas pessoas e revela uma grande riqueza que nem sempre é valorizada (Marques et al. 2010). Assim, o levantamento etnobotânico possibilita a descoberta de novas espécies com potencial inseticida que ainda não foram estudadas pela ciência e valoriza os conhecimentos populares. Tais levantamentos vão desde simples trabalhos com listagens de plantas úteis em determinadas populações, até a compreensão de como essas populações interagem com as plantas (Boscolo 2013).

Ao longo dos anos, várias espécies nativas e domésticas foram estudadas e seus potenciais inseticidas comprovados (Freitas et al. 2012; Alves et al. 2016). Atualmente, a mais conhecida e utilizada como inseticida natural no Brasil é o Nim (Azadirachta indica A. Juss: Meliaceae). Até 
o presente momento foram registradas mais de 200 espécies de insetos controladas por diferentes produtos derivados do Nim, como é o caso de lagartas desfolhadoras, besouros, cigarrinhas e percevejos (Campos et al. 2018; Albiero et al. 2019). O Nim não é nativo do Brasil, é uma planta de origem Asiática, natural de Burma e das regiões áridas da Índia, no entanto seu sucesso aqui no Brasil e em outros países se deve as pesquisas que o reconheceram como eficiente no controle de insetos (Brasil 2013).

Considerando o grande número de espécies tanto da flora como da fauna presentes no Brasil, principalmente no bioma amazônico, o impacto ambiental torna-se mais expressivo quando se utiliza formas de controle de insetos convencionais, ressaltando que muitas espécies ainda não foram catalogadas (Gosch et al. 2017; Araujo et al. 2019). Assim o conhecimento e incentivo à utilização de formas de controle de pragas que sejam menos agressivas se faz necessário visando estimular o uso sistematizado de plantas fitossanitárias no manejo de pragas, a fim de se alcançar uma agricultura mais racional e sustentável, aliada à produção de alimentos mais saudáveis e contribuir na construção de conhecimentos tradicionais (Bleich e Silva 2013).

Muitos produtores orgânicos têm observado resultados positivos com a utilização dos inseticidas botânicos. Esses bioinseticidas apresentam alta eficiência no controle de pragas quando utilizados junto com outros métodos de controle, adotando o Manejo Integrado de Pragas (MIP) e podem reduzir os custos de suas produções, aumentando a rentabilidade e amenizando os impactos ambientais no processo produtivo (Coêlho et al. 2017). Os produtores familiares tornam-se mais propícios ao uso de produtos alternativos, principalmente pelos inseticidas botânicos serem economicamente viáveis (Rogatto 2013). Diante do exposto, o presente trabalho teve por objetivo averiguar e registrar o conhecimento e uso de plantas no controle de insetos-praga pelos produtores familiares de três comunidades rurais do município de Alta Floresta, MT, Vila rural, Guadalupe e Central.

\section{Material e métodos}

O presente trabalho foi desenvolvido em três comunidades rurais do município de Alta Floresta

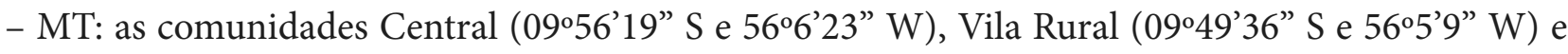
Guadalupe (0953’26” S e 569'43” W) (Figura 1). Estas comunidades são constituídas principalmente por agricultores familiares, que na maioria dos casos são produtores de hortaliças, fruticultura, apicultura, gado de leite, entre outros produtos que são comercializados nas feiras do município e abastecem parte dos mercados locais. 
Figura 1. Localização das comunidades Central, Guadalupe e Vila Rural no mapa de Alta Floresta - MT, Brasil.

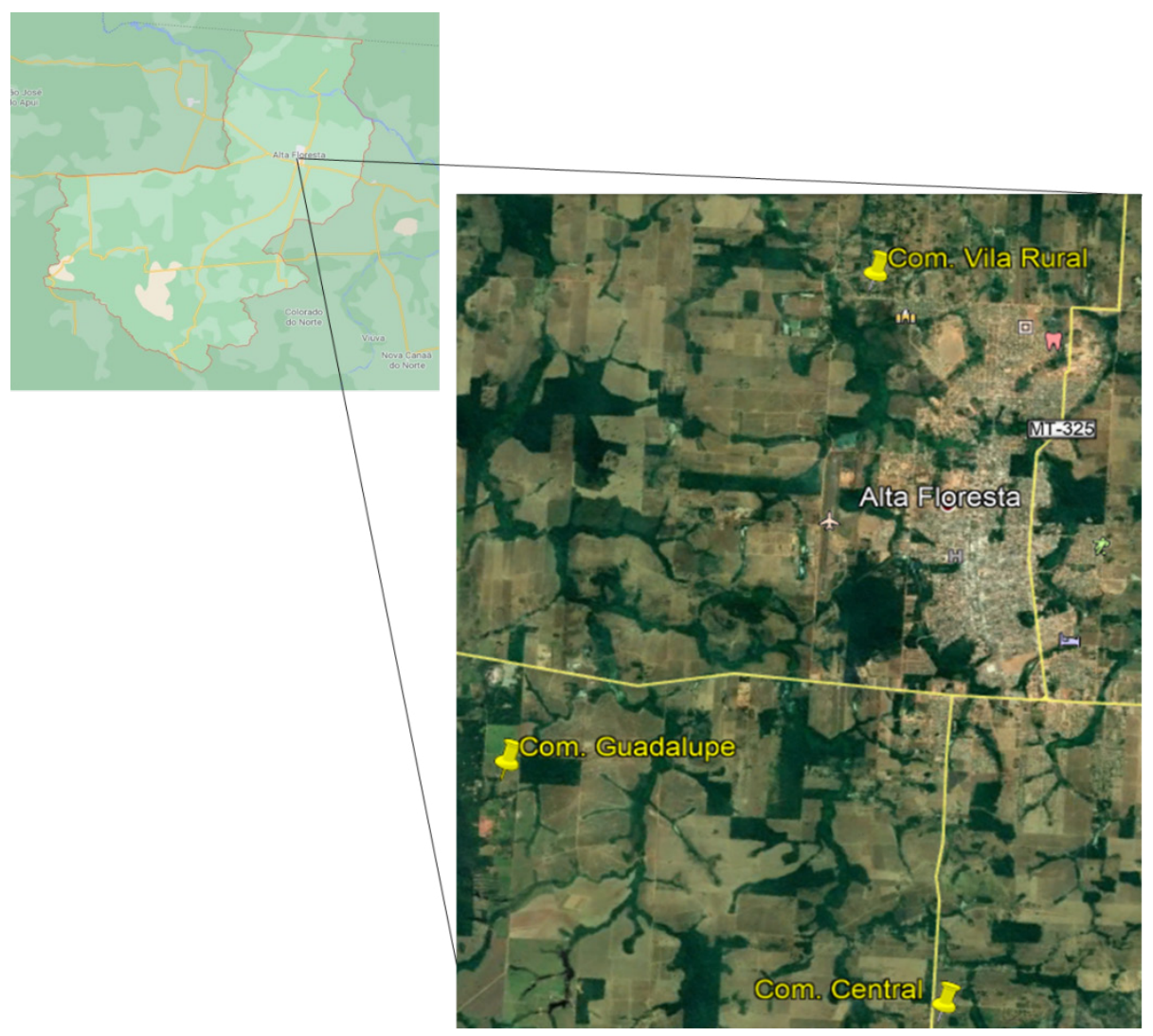

Fonte: Google maps.

Alta Floresta está situada no extremo norte do estado de Mato Grosso, a $830 \mathrm{~km}$ de distância da capital, Cuiabá, foi fundada em 19 de maio de 1976 com famílias na maioria vindas do sul do Brasil para realizar atividades agrícolas (Gervazio 2015; IBGE 2019). Está localizada nas coordenadas 0952'32" S e 5605'10" W.

Antes de iniciar a coleta de dados, o projeto de pesquisa deste estudo foi avaliado e aprovado pelo comitê de Ética e pesquisa - CEP da Universidade do estado de Mato grosso, através da Plataforma Brasil, processo $\mathrm{n}^{\circ}$ 03681718.6.0000.5166 e número do parecer: 3.089.

Foram entrevistados 45 das 326 famílias que residem nas três comunidades em questão (Souza 2019). Essas famílias foram representadas por 26 mulheres e 19 homens. Foram entrevistadas 15 famílias em cada comunidade, escolhidas de forma aleatória, e todos os entrevistados são maiores de idade. Quando os agricultores e agricultoras consentiam em participar da pesquisa, uma cópia do termo de consentimento livre e esclarecido (TCLE) foi entregue aos entrevistados e outra cópia ficou com a pesquisadora, contendo a assinatura do participante.

No total, foram realizadas seis perguntas de forma indireta que discutiam tanto questões sociais, quanto conhecimentos gerais acerca das plantas fitossanitárias. As entrevistas foram realizadas através de um diálogo com os produtores, após leitura, autorização e assinatura do termo de consentimento livre e esclarecido aprovado pelo comitê de ética.

Em meio ao diálogo foram colocadas as perguntas, as quais tinham como objetivo compreender o conhecimento sobre plantas bioinseticidas daquelas populações, fazer um levantamento de quais 
espécies e quais delas são utilizadas em seu cotidiano. As questões levantadas durante as entrevistas (Tabela 1) abordavam também assuntos sobre a origem de seus conhecimentos, quais as formas de obtenção dos bioinseticidas, para quais grupos de insetos são indicadas e se os resultados foram satisfatórios.

Para a identificação das plantas, foram feitas coletas das espécies citadas nas entrevistas, com a indicação dos entrevistados e posteriormente identificadas com o auxílio de bibliografias especificas (Maury 2001; Lorenzi 2002; Lorenzi 2004; Forzza et al. 2015; Albergaria et al. 2019). As plantas citadas pelos moradores das comunidades são comumente encontradas na região, sejam cultivadas nos quintais, encontradas na natureza ou comercializadas no comercio local, como o alho e o fumo.

Para cada uma das espécies citadas durante as entrevistas foi calculado o Valor de Uso (VU), no qual a planta mais importante para uma comunidade é aquela que detém o maior número de usos, sendo determinada pela fórmula $\mathrm{VU}=\Sigma \mathrm{U} / \mathrm{n}$, s $\mathrm{U}$ é o número de citações totais da espécie pelos informantes e n, o número total de informantes que a citaram (Rossato et al. 1999).

Tabela 1. Questionário previamente estabelecido para direcionar a entrevista com os produtores familiares.

\begin{tabular}{l}
\hline \multicolumn{1}{c}{ Questionário } \\
\hline 1. Nome. (opcional) \\
2. Você utiliza alguma planta para controlar insetos? \\
3. Qual a planta mais utilizada para controle de insetos? \\
4. Qual grupo de pragas você costuma controlar com essa (s) planta (s)? \\
5. Como é feito o preparo do inseticida? \\
( ) infusão ( ) maceração ( ) fervido ( ) decocção ( ) in natura ( ) outros. \\
6. Como foi obtido a informação da (s) planta (s) com poder inseticida? \\
( ) Livros/TV/Internet ( ) Familiares/Amigos ( ) Assistência técnica ( ) outros
\end{tabular}

\section{Resultados}

Através do levantamento etnobotânico verificou-se que grande parte da população das comunidades estudadas demonstrou algum conhecimento a respeito de plantas que apresentam efeito inseticida. Dentre os 45 entrevistados das três comunidades observou-se que $42 \%$ conheciam e já haviam utilizado pelo menos uma vez, plantas para controlar ou repelir insetos; $33 \%$ conheciam algumas espécies de plantas com ação inseticida, no entanto nunca utilizou e $25 \%$ não conheciam plantas com ação inseticida. Dos $42 \%$ que já haviam utilizado, 100\% encontraram resultados satisfatórios na utilização de produtos naturais para controlar ou repelir alguma infestação de pragas.

Constatou-se 22 espécies de plantas utilizadas ou conhecidas por esses produtores familiares. As espécies citadas são comumente encontradas nas propriedades rurais da região ou nos supermercados, como é o caso do fumo (Nicotiana tabacum L.) e do alho (Allium sativum L.) (Tabela 2). 
Tabela 2. Descrição das plantas fitossanitárias utilizadas ou conhecidas por agricultores familiares de Alta Floresta - MT.

\begin{tabular}{|c|c|c|c|c|c|c|c|}
\hline $\begin{array}{l}\text { Nome } \\
\text { Popular }\end{array}$ & Nome Científico & Família & Indicação & $\begin{array}{l}\text { Forma de } \\
\text { utilização }\end{array}$ & $\begin{array}{l}\text { Pragas } \\
\text { controladas }\end{array}$ & $\begin{array}{c}\mathrm{N}^{\circ} \text { de } \\
\text { Citações } \\
(\%)\end{array}$ & VU \\
\hline $\begin{array}{l}\text { Alamanda } \\
\text { amarela }\end{array}$ & Allamanda sp. & Apocynaceae & Inseticida & $\begin{array}{l}\text { Extrato da } \\
\text { flor }\end{array}$ & Afídeos & 2,2 & 0,02 \\
\hline Alfavaca & $\begin{array}{l}\text { Ocimum } \\
\text { gratissimum L. }\end{array}$ & Lamiaceae & inseticida & $\begin{array}{l}\text { Extrato da } \\
\text { planta }\end{array}$ & $\begin{array}{l}\text { Pulgão e } \\
\text { cochonilha }\end{array}$ & 2,2 & 0,02 \\
\hline Alho & Allium sativum L. & Amaryllidaceae & Inseticida & $\begin{array}{l}\text { Extrato do } \\
\text { bulbo }\end{array}$ & $\begin{array}{l}\text { Lagarta, pulgões e } \\
\text { cochonilha }\end{array}$ & 2,2 & 0,02 \\
\hline Artemísia & $\begin{array}{l}\text { Artemisia vulgaris } \\
\text { L. }\end{array}$ & Asteraceae & Repelente & $\begin{array}{l}\text { Extrato das } \\
\text { folhas }\end{array}$ & Pernilongo & 2,2 & 0,02 \\
\hline Arruda & Ruta graveolens L. & Rutaceae & Repelente & Chá & $\begin{array}{l}\text { Pragas de } \\
\text { hortaliças em } \\
\text { geral }\end{array}$ & 4,5 & 0,04 \\
\hline $\begin{array}{l}\text { Capim } \\
\text { cidreira }\end{array}$ & $\begin{array}{l}\text { Cymbopogon } \\
\text { citratus Stapf }\end{array}$ & Poaceae & Repelente & $\begin{array}{l}\text { Extrato das } \\
\text { folhas }\end{array}$ & $\begin{array}{l}\text { Pernilongo e } \\
\text { mosca de chifre }\end{array}$ & 4,5 & 0,04 \\
\hline Citronela & $\begin{array}{l}\text { Cymbopogon } \\
\text { winterianus Jowit }\end{array}$ & Poaceae & Repelente & $\begin{array}{l}\text { Extrato das } \\
\text { folhas }\end{array}$ & $\begin{array}{l}\text { Moscas, baratas e } \\
\text { pernilongos }\end{array}$ & 8,0 & 0,08 \\
\hline $\begin{array}{l}\text { Comigo } \\
\text { ninguém } \\
\text { pode }\end{array}$ & Dieffenbachia sp. & Araceae & Repelente & $\begin{array}{l}\text { Plantar } \\
\text { próximo a } \\
\text { residência }\end{array}$ & $\begin{array}{l}\text { Barata, moscas e } \\
\text { mosquitos. }\end{array}$ & 2,2 & 0,02 \\
\hline Cravo & $\begin{array}{l}\text { Syzygium } \\
\text { aromaticum (L.) } \\
\text { Merr. \& L.M.Perry }\end{array}$ & Myrtaceae & Repelente & $\begin{array}{l}\text { Extrato das } \\
\text { flores }\end{array}$ & Pernilongos & 2,2 & 0,02 \\
\hline $\begin{array}{l}\text { Cravo de } \\
\text { defunto }\end{array}$ & Tagetes patula L. & Asteraceae & Inseticida & $\begin{array}{l}\text { Extrato da } \\
\text { planta }\end{array}$ & $\begin{array}{l}\text { Mosquitos e } \\
\text { moscas }\end{array}$ & 2,2 & 0,02 \\
\hline Crotalária & $\begin{array}{l}\text { Crotalaria juncea } \\
\text { L. }\end{array}$ & Fabaceae & Repelente & $\begin{array}{l}\text { Plantar } \\
\text { próximo a } \\
\text { residência }\end{array}$ & Insetos em geral & 2,2 & 0,02 \\
\hline $\begin{array}{l}\text { Erva santa } \\
\text { maria }\end{array}$ & $\begin{array}{l}\text { Dysphania } \\
\text { ambrosioides L. }\end{array}$ & Amaranthaceae & Repelente & $\begin{array}{l}\text { Extrato } \\
\text { da planta, } \\
\text { suco }\end{array}$ & $\begin{array}{l}\text { Pulgão e } \\
\text { cochonilha }\end{array}$ & 4,5 & 0,04 \\
\hline $\begin{array}{l}\text { Feijão de } \\
\text { porco }\end{array}$ & $\begin{array}{l}\text { Canavalia } \\
\text { ensiformis L. }\end{array}$ & Fabaceae & $\begin{array}{l}\text { Repelente e } \\
\text { barreira }\end{array}$ & $\begin{array}{l}\text { Plantar } \\
\text { próximo as } \\
\text { cultivares }\end{array}$ & $\begin{array}{l}\text { Pulgões e mosca } \\
\text { branca }\end{array}$ & 2,2 & 0,02 \\
\hline Fumo & $\begin{array}{l}\text { Nicotiana tabacum } \\
\text { L. }\end{array}$ & Solanaceae & $\begin{array}{l}\text { Repelente e } \\
\text { inseticida }\end{array}$ & $\begin{array}{l}\text { Extrato das } \\
\text { folhas }\end{array}$ & $\begin{array}{l}\text { Pulgão, } \\
\text { cochonilha e } \\
\text { Mosca Branca }\end{array}$ & 33,5 & 0,33 \\
\hline Gergelim & $\begin{array}{l}\text { Sesamum indicum } \\
\text { L. }\end{array}$ & Pedaliaceae & Repelente & $\begin{array}{l}\text { Plantar } \\
\text { próximo as } \\
\text { cultivares }\end{array}$ & $\begin{array}{l}\text { Formigas } \\
\text { cortadeiras }\end{array}$ & 2,2 & 0,02 \\
\hline Guiné & $\begin{array}{l}\text { Petiveria alliacea } \\
\text { L. }\end{array}$ & Phytolaccaceae & Repelentes & $\begin{array}{l}\text { Plantar } \\
\text { próximo a } \\
\text { residência }\end{array}$ & $\begin{array}{l}\text { Mosquitos e } \\
\text { moscas }\end{array}$ & 4,5 & 0,04 \\
\hline Mamoeiro & Carica papaya L. & Caricaceae & Inseticida & $\begin{array}{l}\text { Extrato das } \\
\text { folhas e } \\
\text { suco }\end{array}$ & Pulgão & 2,2 & 0,02 \\
\hline Mamona & $\begin{array}{l}\text { Ricinus communis } \\
\text { L. }\end{array}$ & Euphorbiaceae & Repelente & $\begin{array}{l}\text { Plantar } \\
\text { próximo a } \\
\text { residência }\end{array}$ & $\begin{array}{l}\text { Pragas de } \\
\text { horticultura em } \\
\text { geral }\end{array}$ & 2,2 & 0,02 \\
\hline
\end{tabular}




\begin{tabular}{|c|c|c|c|c|c|c|c|}
\hline $\begin{array}{l}\text { Nome } \\
\text { Popular }\end{array}$ & Nome Científico & Família & Indicação & $\begin{array}{l}\text { Forma de } \\
\text { utilização }\end{array}$ & $\begin{array}{l}\text { Pragas } \\
\text { controladas }\end{array}$ & $\begin{array}{c}\mathrm{N}^{\circ} \text { de } \\
\text { Citações } \\
(\%)\end{array}$ & VU \\
\hline Manjericão & Ocimum L. & Lamiaceae & Repelente & Suco & $\begin{array}{l}\text { Baratas e } \\
\text { pernilongo. }\end{array}$ & 2,2 & 0,02 \\
\hline Nim & $\begin{array}{l}\text { Azadirachta indica } \\
\text { A. Juss. }\end{array}$ & Meliaceae & Inseticida & $\begin{array}{l}\text { Extrato e } \\
\text { óleo }\end{array}$ & $\begin{array}{l}\text { Larva minadora, } \\
\text { pulgão, mosca } \\
\text { branca, lagartas e } \\
\text { vaquinha }\end{array}$ & 22,0 & 0,22 \\
\hline $\begin{array}{l}\text { Pimenta do } \\
\text { reino }\end{array}$ & Piper nigrum L. & Piperaceae & Repelente & $\begin{array}{l}\text { Extrato dos } \\
\text { frutos }\end{array}$ & $\begin{array}{l}\text { Percevejo e } \\
\text { vaquinha }\end{array}$ & 4,5 & 0,04 \\
\hline $\begin{array}{l}\text { Pimenta } \\
\text { malagueta }\end{array}$ & $\begin{array}{l}\text { Capsicum } \\
\text { frutescens L. }\end{array}$ & Solanaceae & $\begin{array}{l}\text { Repelente e } \\
\text { inseticida }\end{array}$ & Suco & $\begin{array}{l}\text { Pulgão e } \\
\text { percevejos. }\end{array}$ & 11,0 & 0,11 \\
\hline
\end{tabular}

As espécies de plantas bioinseticidas mais conhecidas e consequentemente com maiores valores de uso entre os agricultores entrevistados são: fumo, nim, pimenta malagueta, citronela, erva de Santa Maria, guiné e arruda para controlar principalmente pulgões, lagartas, mosquitos, cochonilhas e percevejos. As espécies citadas entre os produtores não são endêmicas da região são todas oriundas de outros estados brasileiros ou até mesmo de outros países.

As principais formas de obtenção dos bioinseticidas relatadas nas entrevistas foram: extratos (maceração do vegetal e deixar curtir em água/álcool por horas ou dias, após, aplicar sobre as plantas infestadas), chás (colocar o vegetal em água fervente e deixar em infusão), planta in sito (fazer o plantio da espécie em determinado local para evitar o ataque dos insetos ou aplicar o extrato para repelir), óleo (Extrair o óleo do vegetal, é o caso do nim) e suco (bater o fruto ou folhas no liquidificador com água).

Os principais grupos de insetos citados nas entrevistas que são passiveis de serem controlados pelas bioinseticidas são: Diptera (moscas, pernilongos e mosquitos), Hemiptera (pulgão, cochonilha, percevejo e moscas-branca), Hymenoptera (formigas), Lepidoptera (lagartas) e Siphonoptera (pulgas).

Em relação a origem do conhecimento, 58\% dos entrevistados relataram que seus conhecimentos a respeito das plantas foram obtidos através de familiares, amigos ou vizinhos; $30 \%$ conheceu o poder das plantas inseticidas através de programas de TV, internet e rádio e $12 \%$ através de assistência técnica.

\section{Discussão}

Através do levantamento etnobotânico das três comunidades rurais de Alta floresta MT, pode-se constatar 22 espécies que podem controlar ou inibir o ataque de insetos. Farias et al. (2016) realizaram levantamento etnobotânico com agricultores familiares do município de Parnaíba-PI e verificaram que esses agricultores conhecem e utilizam um número considerável de espécies botânicas repelentes e/ou inseticidas, foram citadas 17 espécies. Os resultados encontrados evidenciam também que as plantas registradas coincidem com propriedades e aspectos relatados na literatura científica, o que demonstra que os saberes tradicionais e científicos são complementares. O fumo e o nim foram os mais citados entre os agricultores, assim como no presente estudo. 
O uso abundante do fumo pelos agricultores foi constatado por Morais (2011), sendo que o grande consumo como forma de controle de insetos se deve a eficiência da espécie no controle das pragas, essa eficiência relacionada a presença da nicotina em sua constituição, tal substancia se liga aos receptores do neurotransmissor acetilcolina no neurônio pós-sinaptico promovendo hiperexcitação e descoordenação muscular no inseto (El-Wakeil 2013).

O nim foi a segunda planta mais citada entre os produtores, a ação inseticida acontece por apresentar muitos compostos ativos, dos quais a salanina, azadiractina e nimbolina, entre outros (Carneiro 2013). Estes metabólitos vem demonstrando alta eficácia no combate de diversas pragas e doenças que atacam plantas e animais (Nhaga et al. 2018), sendo que mais de 200 espécies de pragas foram controlados pelos extratos de nim, como é o caso das lagartas desfolhadoras, besouros, pulgões e percevejos (Albiero et al. 2019), tornando-se assim uma ferramenta eficaz para os pequenos agricultores, uma vez que é economicamente viável e ecologicamente segura para o manejo das culturas no campo (Uchoa 2018).

A pimenta malagueta está entre as plantas mais citadas pelos agricultores como sendo eficiente no controle de insetos. Vinayaka et al. (2010); Guimarães et al. (2014) e Gomes et al. (2017) comprovam a efetividade de extratos de pimenta malagueta através de estudos realizados com as mesmas e detecção da ação inseticida sobre insetos como Aphis craccivora (Cook) e Aedes aegypti (L.).

A citronela já é conhecida pelo poder repelente do seu óleo essencial (Castro e Ramos 2013), e apresenta efeito na redução da sobrevivência de adultos de coleópteros (Brito et al. 2017), além de apresentar efeito repelente contra mosquitos e moscas (Harismah et al. 2017).

A arruda, a erva-de-santa-maria, capim cidreira e guiné, também foram citadas pelos entrevistados como sendo plantas conhecidas como bioinseticidas, embora com menor representatividade entre as plantas citadas. Martí et al. (2010) observaram que o extrato aquoso de arruda repele formigas e ratos, além de combater pulgões. O extrato aquoso de capim cidreira inibe a ação de coleobrocas em sementes armazenadas, além de apresentar atividade antifúngica (Araújo et al. 2019). Rauber et al. (2017) verificaram através de pesquisas etnobotanicas que o guiné é utilizado como extratos para controlar insetos na produção agrícola, assim como o alho o cravo-de-defunto, mamona, pimentado-reino, são todas espécies utilizadas como plantas medicinais que estão sendo eficientes no controle de pulgões, lagartas e percevejos.

A falta de conhecimento dos produtores por espécies de plantas endêmicas da Amazônia que apresentam ação inseticida é justificada pelo fato de Alta Floresta ser um município muito jovem. Foi fundado em 1976, a maior parte da população local veio de outros lugares do país, principalmente da região sul do Brasil e trouxeram consigo seus conhecimentos e tradições (Silva e Rauber 2018), além do escasso número de pesquisas com espécies amazônicas para este fim, tendo em vista a grande diversidade de plantas existentes na Amazônia brasileira é possível detectar grande potencial para produção de inseticidas botânicos (Santos 2014).

A principal fonte de conhecimento sobre plantas inseticidas para 58\% dos entrevistados foi através de familiares. Araújo et al. (2018) consideram que o aprendizado etnobotânico de agricultores é geracional e familiar, pois 53,33\% dos entrevistados de sua pesquisa também aprenderam com familiares. 


\section{Conclusões}

O presente trabalho confirmou o conhecimento etnobotânico dos agricultores e foi possível perceber como as comunidades ainda estão intimamente ligadas ao uso de plantas para controlar uma diversidade de espécies de pragas, no entanto esse conhecimento é limitado a espécies não nativas da região. Constatou-se a necessidade de mais estudos e divulgação para estimular o uso destes produtos naturais.

\section{Agradecimentos}

A Universidade do Estado de Mato Grosso e as fontes financiadoras Capes e Fapemat.

Participação dos autores: SOB - Proposta do projeto, revisão da literatura, coleta de dados, análise dos resultados; redação do manuscrito; MKS - revisão da literatura, coleta de dados e análise dos resultados; redação do manuscrito; JG - orientação, proposta do projeto, revisão da literatura, análise dos resultados, orientação da redação do manuscrito, revisão do manuscrito.

Aprovação ética e licenças: O presente estudo foi avaliado e aprovado pelo comitê de Ética e pesquisa - CEP da Universidade do estado de Mato grosso, através da Plataforma Brasil, processo ${ }^{\circ}$ 03681718.6.0000.5166 e número do parecer: 3.089.

Disponibilidade dos dados: Os dados desta pesquisa então disponíveis na biblioteca da Universidade do Estado do Mato Grosso em formato de monografia digital e impresso.

Fomento: O presente estudo foi fomentado pelas Capes (Coordenação de Aperfeiçoamento de Pessoal de Nível Superior) e Fapemat (Fundação de Amparo à Pesquisa do Estado de Mato Grosso) com fornecimento de bolsas de estudo.

Conflito de Interesses: Não há conflitos de interesse.

\section{Referências}

Albergaria ET, Silva MV, Silva AG. 2019. Ethnobotany survey of medicinal plants in rural communities located in the Protected Area of Tatu-Bola, Lagoa Grande town, PE - Brazil. Revista Fitos,13(2): 137-154.

Albiero B. 2019. Insecticide potential of essential oils of endro (Anethum graveolens) and nim (Azadirachta indica) in the control of Sitophilus zeamais. Brazilian Journal of Development, 5:21443-21448.

Alves CAB, Silva S, Belarmino NALA, Souza RS, Silva DR, Alves PRR, Nunes GM. 2016. Comercialização de plantas medicinais: um estudo etnobotânico na feira livre do município de Guarabira, Paraíba, nordeste do Brasil. Gaia Scientia, 10(4):390-407.

Araújo AKO, Dos Santos SGR, Maurício SML, Maria SSA, Nascimento LC. 2019. Sanidade e qualidade fisiológica de sementes de Chorisia Glaziovii O. Kuntze tratadas com extratos vegetais. Ciência Florestal, 29(2):649-659.

Araújo ÉASGO, Fernandes SDC, Roque F, Delgado MN. 2018. Levantamento de plantas fitossanitárias utilizadas no manejo de pragas agrícolas. Revista brasileira de agroecologia, 13(4):163-174.

Batista LA, Brandão EG, Rosas LV, Pinto MN, Pantoja TMA, Araújo TV, Lima RA. 2019. Levantamento de plantas medicinais utilizadas contra parasitoses e verminoses intestinais no município de Atalaia do Norte - AM. Biota Amazônia, 9(2):35-39. http://dx.doi.org/10.18561/2179-5746/biotaamazonia.v9n2p35-39.

Bleich ME, Silva CJ. 2013. Caracterização dos fragmentos florestais amazônicos remanescentes na microbacia hidrográfica do rio Taxidermista I em Alta Floresta, MT. Biotemas, 26(4):45-51. 
Boscolo OH. 2013. Para comer, para beber ou para remédio? Categorias de uso múltiplo em Etnobotânica. Cadernos UniFOA, 8(1):61-67.

Brandelli CLC. 2017. Plantas medicinais: Histórico e Conceito. In: Farmacobotânica: Aspecto teórico e aplicação, Artmed, Porto Alegre: S. S. Monteiro, p. 1.

Brasil RB. 2013. Aspectos botânicos, usos tradicionais e potencialidades de Azadirachta indica (neem). Enciclopédia biosfera, Centro Científico Conhecer, 9(17):3252-3268.

Brito R, Lopes HM, Paulo HH, Lima ACF, Fernandes MCA, Brandão A. 2018. Utilização de óleos essenciais de Capimlimão (Cymbompogon citratus), Citronela (Cymbopogon nardus) e Óleo de Nim (Azarirachta indica) no Controle de Insetos e Microorganismos. Cadernos de Agroecologia, 13(1):1-7.

Campos CV, Norberg AN, Sanches FG, Duarte AC, Freire NMS. 2018. Biological control of Haematobia irritans fly in bovine by application of aqueous extract obtained from nim leaves (Azadirachta indica). Interdisciplinary Scientific Journal, 5(4):189-197. http://dx.doi.org/10.17115/2358-8411/v5n4a13.

Carneiro SMTPG. 2013. Efeito de extratos de folhas e do óleo de nim sobre o oídio do tomateiro. Summa Phytopathologica, 29(3):262-265,

Castro LO, Ramos RLD. 2013. Principais gramíneas produtoras de óleos essenciais: Cymbopogon citratus (DC.) Stapf., capim-cidró, Cymbopogon martinii (Rox.), Porto Alegre: Fepagro. 23 p.

Coêlho MDG, Xavier TB, Costa JF, Maciel LTR, Bozo LSO, Coêlho FAS, Akisue G. 2017. Avaliação do uso de extratos vegetais para controle da hemoncose em ovinos naturalmente infectados. Revista Ambiente e Água, 12(2): 331-339. http://dx.doi.org/10.4136/ambi-agua.2020.

El-Wakeil NE. 2013. Botanical pesticides and their mode of action. Gesunde pflanzen, 65:125-149. http://dx.doi. org/10.1007/s10343-013-0308-3.

Farias JC, Bomfim BLS, Fonseca-Filho IC, Silva PRR, Barros RFM. 2016. Plantas inseticidas e repelentes utilizadas em uma comunidade rural no Nordeste brasileiro. Revista espacios, 37(22):6-17.

Forzza RC et al. 2015. Introdução. In: LISTA DE ESPÉCIES DA FLORA DO BRASIL. Jardim Botânico do Rio de Janeiro. Disponível em: <http://floradobrasil.jbrj.gov.br/.> Acesso em: 12 fev. 2020.

Freitas AVL, Coelho MFB, Azevedo RAB, Maia SSS. 2012. Os raizeiros e a comercialização de plantas medicinais em São Miguel, Rio Grande do Norte, Brasil. Revista brasileira Biociência, 10(2):147-156.

Gervazio W. 2015. Agrobiodiversidade e qualidade do solo em quintais agroflorestais urbanos na cidade de Alta Floresta - MT. 2015. 136f. Dissertação (Mestrado em Biodiversidade e Agroecossistemas Amazônicos). Faculdade de Ciências Biológicas e Agrárias da Universidade do Estado de Mato Grosso, Alta Floresta.

Gomes FHT, Bleicher E, Costa JVTAl, Pontes FSS, Cysne AQ. 2017. Atividade inseticida de extratos vegetais sobre o pulgão-preto do feijoeiro. Revista de ciências agroambientais, 15(1):75-81.

Gosch MS, Ferreira ME, Medina GS. 2017. The role of the rural settlements in the Brazilian savanna deforestation process. Journal of Land Use Science, 12:55-70.

Guimarães SS, Potrich M, Silva ERL, Wolf J, Pegorini CS, Oliveira TM. 2014. Ação repelente, inseticida e fagoinibidora de extratos de pimenta dedo-de-moça sobre o gorgulho do milho. Arquivos do Instituto Biológico, 81(4):322-328. https:// doi.org/10.1590/1808-1657000172013

Harismah K, Vitasari D, Mirzaei M, Fuadi AM, Aryanto YH. 2017. Protection capacity of mosquito repelente ink from citronella (Cymbopogon nardus L.) and clove leaf oils (Syzygium aromaticum) againts Aedes aegypti. AIP Conference Proceedings, 18(1)1-6. https://doi.org/10.1063/1.4985468

IBGE (Instituto Brasileiro de Geografia e Estatística). 2019. Censo Demográfico 2010. Site do IBGE. 
IBGE (Instituto Brasileiro de Geografia e Estatística). 2019. Cidades 2019. Site do IBGE.

Lorenzi H. 2002. Plantas medicinais no Brasil: nativas e exóticas. Instituto Plantarum, Nova Odessa, SP.

Lorenzi H. 2004. Plantas Ornamentais no Brasil: arbustivas, herbáceas e trepadeiras, Instituto Plantarum, Nova Odessa, SP.

Marques MS, Lacerda VD, Giraldi M, Ulysséa MA, Assis ALAA, Peroni N, Hanazaki N. 2010. Valorização do conhecimento etnobotânico dos moradores do sertão do ribeirão, Florianópolis/SC - Brasil. Revista Eletrônica de Extensão, 7(9):4758. https://doi.org/10.5007/1807-0221. v7n9p47.

Martí JF, Küster A, Quemel P. 2010. Agroecologia, manejo de pragas e doenças: Agricultura familiar, Agroecologia e Mercado, Fundação Konrad Adenauer, n. 6. Ceará, 44 p.

Maury EACR. 2002. Guia das Plantas Medicinais. São Paulo: Rideel, 2001.

Nhaga AO, Pinto CM, Salles MGF, Pinto ORO, Sousa FA. 2018. Controle da cochonilha de escama da palma forrageira com o uso de extrato de nim. Enciclopédia biosfera, 15(28):332-340. https://DOI.org/ 10.18677/EnciBio_2018B28.

Rauber AC, Franzener G, Leandrini JA. 2018. Conhecimento etnobotânico sobre plantas medicinais para uso agrícola de agricultores familiares do Núcleo Regional Luta Camponesa da Rede Ecovida de Agroecologia. Cadernos de Agroecologia, 13(1):1-6.

Rossato SC, Leitao-Filho HF, Begossi A. 1999. Ethnobotany of caiçaras of the atlantic forestcoast (Brazil). Economic Botany, 53(4): 387-395.

Santos ACV. 2014. Plantas inseticidas ocorrentes na Amazônia como alternativa de controle de Spodoptera frugiperda e Sitophilus zeamais. 2014. 62f. Dissertação (Área de concentração em produção vegetal) - Universidade Federal do Acre, Rio Branco.

Silva FF, Rauber M. 2018. Memórias, práticas e degradações garimpeiras em Alta Floresta-MT. Revista Eletrônica das Faculdades de Alta Floresta, 7(2):28-48.

Souza VC. 2019. Caracterização de agroecossistemas utilizados por agricultores familiares em comunidades rurais no portal da Amazônia - Mato Grosso: Agrobiodiversidade, alimentação e geração de renda. 2019. 54f. Dissertação (Mestrado em Agroecologia e Desenvolvimento Rural) Universidade federal de São Carlos, Araras.

Takeara R, Gonçalves R, Ayres VFS, Guimarães AC. 2017. Biological properties of essential oils from the Piper species of Brazil: A Review. Itacoatiara: Intechopen, 81p.

Uchoa LR, Almeida Filho II, Souza JP, Santos CF, Santos DL. 2018. Extratos de nim no controle da Spodoptera frugiperda em milho. Revista Verde de Agroecologia e Desenvolvimento Sustentável, 13(2):163-169.

Vinayaka KS, Prashith Kekuda TR, Nandini KC, Rakshitha MN, Martis R, Shruthi J, Nagashree GR, Anitha B. 2010. Potent insecticidal activity of fruits and leaves of Capsicum frutescens (L.) var. longa (Solanaceae). Der Pharmacia Lettre, 2(4):172-176. 